Fecha de recepción: 17 de julio de 2020

Sugerencia de citación: Carnut, L., Taborda-Texeira, G. A y Araújo-Valencia, G. (2021). O pensamento econômico em saúde de Hésio Cordeiro sobre o financiamento da saúde pública no Brasil e a intervenção anticíclica em Claudio Napoleoni. tiempo\&economía, 8(1), 95-122. https://doi.org/10.21789/24222704.1629
Vol. 8 N. ${ }^{\circ} 1$

Enero - Junio del 2021

pp. $95-122$
HISTORIA ECONÓMICA,EMPRESARIAL Y DEL PENSAMIENTO

TIEMPO \& ECONOMÍA

DOI:

https://doi.org/10.21789/24222704.1629

\title{
0 pensamento econômico em saúde de Hésio Cordeiro sobre o financiamento da saúde pública no Brasil e a intervenção anticíclica em Claudio Napoleoni*
}

The Economic Thought of Hésio Cordeiro on the Financing of Public Health in Brazil and the Countercyclical Intervention by Claudio Napoleoni

Leonardo Carnut

Universidade Federal de São Paulo, Brasil http://orcid.org/0000-0001-6415-6977 leonardo.carnut@unifesp.br

Glauce Araújo Taborda Teixeira Instituto do Câncer do Estado de São Paulo, Brasil http://orcid.org/0000-0001-8593-5232 glauce.taborda@gmail.com

Gabriela Araújo Valencia IQVIA Brasil

http://orcid.org/0000-0002-5537-163X gabivalenciagabi@gmail.com

Agradecemos as contribuições feitas por Alberto Guilherme Faria de Oliveira, Fernando Augusto Vieira, Marcos Leite da Costa, Mauro Yoshitsugu Sokei, Renata Coutinho Conserva e Vanessa Vitto de Oliveira. 


\section{Resumo}

Neste artigo, realiza-se uma reflexão teórica sobre como Hésio Cordeiro, um dos sanitaristas mais influente dos anos de 1980, tratou o problema do financiamento da saúde em sua obra, sob a influência de Claudio Napoleoni. Para isso, usou-se o ensaio como modalidade textual e, como método, a análise de conteúdo. $\mathrm{O}$ texto está estruturado em três partes. A primeira descreve uma breve biografia intelectual e político-institucional de Hésio Cordeiro e de Claudio Napoleoni a fim de situá-los historicamente. A segunda versa sobre como Cordeiro foi inspirado por Napoleoni ao analisarmos as soluções anticíclicas para pensar a saúde pública nos anos de 1980 . Por último, a terceira aponta uma breve consideração final para valorizarmos a importância de Cordeiro como um intelectual propositor de soluções progressistas para a saúde no seu tempo.

Palavras-chave: financiamento dos sistemas de saúde, economia e organizações de saúde, economia da saúde, saúde pública, história econômica.

Códigos JEL: I15, B20, H10.

\section{Abstract}

This paper introduces a theoretical reflection about the problem of health financing from the perspective of Hésio Cordeiro, one of the most important sanitarians of the 1980s in Brazil, and how this author was influenced by the work of Claudio Napoleoni. For this purpose, the essay was used as textual unit and content analysis was incorporated as methodology. The content is structured in three parts. The first describes a brief intellectual and political-institutional biography of Cordeiro and Napoleoni, trying to situate both authors in their historical contexts. The second part shows how Cordeiro was inspired by Napoleoni's work, which influenced the way Cordeiro addressed countercyclical solutions to rethink public health issues during the 1980s. The third points to a brief final consideration on the importance of Cordeiro as an intellectual who proposed progressist solutions for health back in his time.

Keywords: Health systems financing, economics and health organizations, health economics, public health, economic history.

JEL Codes: I15, B20, H10. 
TIEMPO \& ECONOMÍA

Vol. 8 N. ${ }^{\circ} 1$ | Enero - Junio del 2021

pp. $95-122$

\section{INTRODUÇÃO}

Com a Constituição de 1988 no Brasil, diversas políticas sociais que constituem uma tentativa de construção de um Estado de Bem-Estar Social foram "ensaiadas"1 (Boschetti, 2016). Nesse contexto, diversos direitos sociais ${ }^{2}$ foram erigidos, dos quais o direito à saúde, que, certamente, foi aquele que ganhou maior expressão concreta ${ }^{3}$. Por meio de um conjunto de forças sociais articuladas ${ }^{4}$ (Paim, 2008), o Sistema Único de Saúde (SUS), expressão material desse direito, foi contemplado na Constituição de 1988, contudo com diversos problemas em seu devir histórico. Assim, sob a perspectiva historiográfica, pode-se dizer o SUS nasceu em um momento de crise do capitalismo internacional com consequências importantes para os países latino-americanos, especialmente para o Brasil (Santos, 1990).

Uma discussão muito importante no período de transição democrática no Brasil (1980-1990) se dava pela característica dependente da economia brasileira, especialmente relacionada à discussão entre cepalinos $^{5}$ e marxistas ${ }^{6}$ sobre como construir a soberania nacional nos anos da redemocratização do país (Paim, 2007). Em se tratando do setor saúde e, consequentemente, da construção de um sistema de saúde público e universal, a questão da soberania nacional era crucial (Mathias, 2020) e estava relacionada à produção de insumos nesse setor (químico-farmacêutico-biotecnológico, materiais e equipamentos médico-odontológicos-veterinários, assim como a própria produção de serviços) (Gadelha, 2012;

1 Segundo Boschetti (2016), a mera positivação jurídica dos direitos sociais não é o suficiente para dizer que, no Brasil, houve um Estado de Bem-Estar Social. A autora afirma que a falta de sinergia das políticas sociais, seu subfinanciamento e a constituição histórica do que significa o "bem-estar social" no capitalismo invalidariam essa tese.

2 Dispostos no artigo $6^{\circ}$ na Constituição Federal de 1988 (direito à educação, à saúde, à alimentação, ao trabalho, à moradia, ao transporte, ao lazer, à segurança, à previdência social, à proteção à maternidade e à infância, e à assistência aos desamparados).

3 Reconhece-se que o direito à saúde foi o direito da seguridade social que mais ganhou concretude na vida dos brasileiros (Bravo, 2015) em função da criação do Sistema Único de Saúde (SUS) e sua alta capilaridade em todo o território nacional nos últimos 20 anos, segundo dados de Miranda (2017). A previdência social e a assistência social (os dois outros direitos que compõem o "bloco" da seguridade social), por seu caráter focalizado e sua dependência de condicionalidades claras (contribuição, velhice, pobreza legalmente comprovada etc.), não têm essa materialidade na vida de todos os brasileiros como acontece no caso do "direito à saúde" efetivado pelo SUS.

4 Forças sociais articuladas para consolidação do SUS (movimento da reforma sanitária brasileira, eclesiais de base da igreja, partidos de esquerda, em especial o Partido Comunista Brasileiro, PCB, entre outros) (Paim, 2008). Essa época foi marcada por movimentos de redemocratização do país, com a idealização da reforma da sociedade brasileira. A democratização na saúde foi fortalecida no movimento pela reforma sanitária, avançando e sistematizando suas propostas na $8^{\text {a }}$ Conferência Nacional de Saúde (Fundação Nacional de Saúde, Funasa, 2017).

5 Os cepalinos eram aqueles que, em geral, defendiam o desenvolvimentismo nacionalista.

6 Os marxistas defendiam, em geral, a mescla reforma-revolução. 
Raw, 2007). Por isso, para os sanitaristas que pensavam "o econômico", era um tema a ser problematizado e conduzido do ponto de vista político.

Assim, imbuídos de uma perspectiva mais alinhada à social democracia (Paim, 2008), pois se restringiam à institucionalidade estatal, a condução política desse impasse (predominantemente proposta pelo movimento da Reforma Sanitária Brasileira) foi elaborar soluções ligadas às estratégias de intervenção anticíclica. A adoção de uma política econômica anticíclica consiste no conjunto de ações governamentais voltadas a impedir, sobrepujar ou minimizar os efeitos do ciclo econômico. Compreende-se por "ciclo econômico" as flutuações da atividade econômica, inerentes à economia e caracterizadas pela alternância de períodos de ascensão (picos) e períodos de recessão (vales), isto é, o ponto mais baixo do ciclo. Os ciclos econômicos decorrem da sobreacumulação e da superprodução, às quais se seguem expectativas de declínio da taxa de lucro (ou de que a taxa de lucro seja menor que a taxa de juros), o que provoca a redução de investimentos e a desaceleração do nível de atividade (Napoleoni, 1979).

É importante delimitar que a "transição democrática", também chamada de "redemocratização"7 (Codato, 2005) —período no qual a análise deste estudo se assenta-, foi o momento em que houve o processo de reabertura democrática lenta e gradual com início no governo do general João Baptista Figueiredo (1979-1985). A partir desse governo, o pluripartidarismo foi reestabelecido e o contexto internacional agravado pela crise econômica, pela inflação e pela recessão. Essa situação fez acirrar os partidos de oposição ao regime e instigou à participação popular na vida pública de forma mais intensa, da mesma forma que se fortaleceram os sindicatos e as entidades de classe (Longhi \& Gentile, 2019). Nesse período, a crítica ao sistema de saúde gestada no governo militar se instituiu, promovendo a organização de diversos movimentos sociais na defesa do direito à saúde pública e universal (Paiva \& Teixeira, 2014).

Assim, nesse esteio, este artigo objetiva realizar uma reflexão teórica sobre como o problema do financiamento da saúde foi tratado por um dos sanitaristas, à época, mais influente sobre o tema, chamado Hésio Cordeiro, e como uma das suas obras foi influenciada pelo pensamento econômico de Claudio Napoleoni. Hésio Cordeiro é portador de um pensamento que problematiza a saída keynesiana de intervenção anticíclica na economia

7 Em termos historiográficos, essa é a segunda redemocratização ocorrida no Brasil. A primeira data de 1945, no contexto do capitalismo monopolista. 
brasileira para promover a construção de um sistema de saúde dotado da infraestrutura necessária em direção à nacionalização. Para tanto, recorre-se à análise de um texto fundamental desse autor que visa a esse procedimento comparativo: "Financiamento do setor de saúde: proposta para a transição democrática", de 1985, publicado na revista Saúde em debate, principal revista de saúde pública que registrou a discussão teórico-política da saúde no período da redemocratização no Brasil (Cordeiro, 1985).

Para comparar a proposta keynesiana de Cordeiro com a compreensão sobre o que é uma intervenção anticíclica, é utilizado o texto do autor Claudio Napoleoni "A intervenção anticíclica", capítulo do livro Curso de Economia Política, do mesmo autor, de 1979, obra de grande penetrabilidade no Brasil (Napoleoni, 1979). Destacado marxista e economista italiano, Napoleoni foi chamado por Giorgio Fuà ${ }^{8}$ para ser professor ordinário da disciplina de Política Econômica da Faculdade de Economia e Comércio da Universidade de Ancona, para, em seguida, passar para a Faculdade de Ciências Políticas da Universidade de Turim. Napoleoni estava interessado principalmente em problemas teóricos da economia e esteve ligado ao Partido Comunista Italiano (PCI) (Collona, 2000; Reichlin, 2008). Esse partido apresentava, na década de 1970-1980, forte influência no pensamento sanitário brasileiro (Dantas, 2007; Escorel, 1999) e, por isso, Napoleoni foi eleito como autor para a comparação neste trabalho.

Assim, este artigo é divido em três partes, com a utilização do ensaio como modalidade de escrita (Adorno, 2003; Starobinski, 2011) e da análise de conteúdo clássica como método de análise (Bauer, 2000), cujos corpora que compuseram as unidades de análise versavam sobre a perspectiva anticíclica em Hésio Cordeiro. A primeira descreve uma breve biografia intelectual e político-institucional de Hésio Corderio e Claudio Napoleoni a fim de situá-los historicamente, além da influência de Napoleoni na obra de Cordeiro. A segunda versa sobre como este último foi inspirado por Napoleoni ao analisarmos as soluções anticíclicas para pensar a saúde pública nos anos de 1980. Por último, a terceira aponta uma breve consideração final para valorizarmos a importância de Cordeiro como um intelectual propositor de soluções progressistas para a saúde no seu tempo. para a Europa das Nações Unidas, presidida, à época, por Gunnar Myrdal. Entre 1983 e 1986, Fuà foi presidente da Sociedade Italiana de Economistas. 


\section{CORDEIRO E NAPOLEONI: UMA BREVE BIOGRAFIA INTELECTUAL E POLIITICO-INSTITUCIONAL}

Hésio de Albuquerque Cordeiro é médico, brasileiro, nascido em Juiz de Fora (Minas Gerais). Entre as várias atuações na área de saúde pública, teve um importante papel precursor na Constituição Federal brasileira de 1988. Ele coordenou e presidiu trabalhos da $8^{a}$ Conferência Nacional de Saúde e ajudou na defesa em relação à saúde como dever do Estado, de forma universalizada e com integralidade da assistência à população, assim como, na participação e no controle dos serviços de saúde por seus usuários (Fiocruz, 2014).

Graduou-se na Faculdade de Ciências Médicas pela Universidade do Estado do Rio de Janeiro (1965), com mestrado em Saúde Coletiva pela mesma universidade (1978) e doutorado em Medicina Preventiva pela Universidade de São Paulo (1981). Foi presidente do Instituto Nacional de Assistência Médica e Previdência Social (Inamps) de 1985 a 1988, e, em 1990, candidatou-se a deputado federal pelo Partido Democrático Trabalhista (Portal Fiocruz, 2020).

Sem muito êxito no âmbito político, seguiu sua liderança no mundo educacional. Foi reitor da Universidade Estadual do Rio de Janeiro entre 1992 e 1995. Foi presidente do Conselho Nacional de Educação de 1966 a 1967 e conselheiro até 1968. Foi diretor do curso de Medicina da Universidade Estácio de Sá de 2002 a 2006. Atualmente, Cordeiro é coordenador do mestrado profissional dessa universidade e coordena também a "seção saúde" da Fundação Cesgranrio. A partir de 2007, Cordeiro foi nomeado diretor da Agência Nacional de Saúde Suplementar no governo Lula (Portal Fiocruz, 2020).

Sua atividade como pesquisador não é menos notável. Dessa atividade resultaram inúmeros artigos publicados em revistas nacionais e internacionais, e dois livros, hoje clássicos em seus respectivos campos temáticos e amplamente utilizados no Brasil e na América Latina como referências obrigatórias. O principal deles é $A$ indústria da saúde no Brasil, publicado originalmente em 1980 com segunda edição em 1986 (Buss, 1988).

O contexto em que a análise dos textos deste artigo se insere é a década de 1980. Nesse período, exatamente em 21 de maio de 1985, Hésio assumiu a administração do Inamps, a mais importante agência de assistência médica da América Latina, e a terceira do mundo. Foi o primeiro sanitarista a ocupar esse cargo colocando-se como um grande desafio (Buss, 1988). 
Cordeiro foi clandestinamente vinculado ao Partido Comunista Brasileiro (PCB) e nos idos de 1964, teve alguma ação nas manifestações de rua contra o Golpe Militar (Centro de Estudos Brasileiros em Saúde, Cebes, 2014). O PCB reunia grande parte dos sanitaristas à época, entre os quais Hésio era um deles. O PCB apresentou, na década de 1980, uma influência do Partido Comunista Italiano (PCI) considerável traduzido na linha de compreensão do avanço do socialismo à luz do eurocomunismo.

Escorel (1999) demonstra bem como os sanitaristas da América Latina buscavam núcleos sobre pensamento crítico na tentativa de realizar intercâmbios políticos e intelectuais principalmente ligados ao PCl. O Cebes publicava os livros dos principais intelectuais ligados ao $\mathrm{PCl}$ e se tornaria, no âmbito da saúde, o centro de estudos que, sob a hegemonia do PCB, mas aberto a todas as correntes de esquerda, seria capaz de construir uma proposta alternativa de política de saúde.

Já o economista marxista italiano Claudio Napoleoni foi professor de Economia Política e História das Doutrinas Econômicas na Universidade de Turim (Marxists Internet Archive - Mia, 2020). Interessado no trabalho de investigação teórica sobre a economia política, o autor produziu um cabedal de obras sobre o tema, entre as quais, Elementi di Economia Politica (traduzida ao português com o título Curso de Economia Política) de 1967, ganhando alcance mundial.

Ao final da Segunda Guerra Mundial, o autor ingressou no PCl, integrando sua comissão econômica. Ele era um grande crítico da posição da esquerda italiana quanto ao fenômeno da globalização. Para Napoleoni, não mudaram só os poderes, as necessidades e as expectativas após a globalização, mas também "desapareceram" ${ }^{9}$ os velhos instrumentos da ação político-econômica da esquerda: a moeda nacional, as funções redistributivas do Estado, a economia pública, a fronteira nacional. Para o autor, somente esses instrumentos haviam garantido ao cidadão alçar espaço real na representação pública e, ainda, incluir-se no sistema de deveres e direitos (Collona, 2000; Reichlin, 2008).

9 Essa afirmação de Napoleoni é bastante controversa. Uma análise marxista mais ortodoxa, por exemplo, defenderá que esses "instrumentos" da política econômica existem, contudo apresentam eficácia limitada em países dependentes em relação ao império capitalista. Nesses países dependentes, o "peso da revolução" conta muito no reordenamento do poder político e na assunção de medidas reformistas de longo prazo articuladas dialeticamente. No entanto, Napoleoni era uma "marxista keynesiano" e, portanto, depositava muita esperança no Estado capitalista, na transição progressista pacífica e na mudança da correlação de forças pela via eleitoral-institucional aos moldes da democracia (burguesa). 
Por isso, defensor de um novo humanismo, ele viveu a política, assim concebida, como uma "dramaticidade da dúvida" do porvir histórico. Para Reichlin (2008), Napoleoni parece hoje profético (há 37 anos), pois previa que havia chegado a uma espécie de "crise histórica" por causa do advento de uma forma inédita de supercapitalismo, que tinha como consequência a derrocada do chamado "compromisso entre democracia e capitalismo". Como aponta Bellofiore (1991), Napoleoni tinha uma abordagem crítica à economia política sobre as saídas de reformulação reformista que havia conseguido moderar os desequilíbrios do mercado com a função redistribuidora do Estado social.

Não por isso, como aponta Reichlin (2008), Napoleoni já previa as consequências da virada que ocorreu nos anos 1970 e que, infelizmente, com incertezas e atrasos, os dirigentes do $\mathrm{PCl}$ entenderam muito pouco. Uma virada que depois se configurou como algo mais do que uma mudança do paradigma da economia: como o advento de uma autêntica revolução econômica e política, ainda que conservadora, e da qual hoje vemos o resultado desastroso.

Napoleoni e sua relação com o PCl foi intensa. Já no caminho eurocomunista do partido, sua crítica ácida ao reformismo por um lado e sua visão revisionista do marxismo por outro provocaram acalorados debates. É pertinente lembrar que o eurocomunismo, de uma maneira renovadora, é uma perspectiva teórico-política que realiza um afastamento comum em relação à ideia de revolução como "um eventual golpe de mão de uma vanguarda decidida a tudo para penetrar na cidadela do poder, aproveitandose de suas rachaduras" (Mondaini, 2006, p. 3). Em troca, os eurocomunistas optam por outra concepção assentada na necessidade de estruturação de "um bloco histórico que se revele capaz de substituir gradualmente, e por via pacífica, a velha classe dirigente na direção do Estado, em seu todo econômico e político" (Mondaini, 2006, p. 3).

Em 1951, Napoleoni afastou-se do PCl e dedicou-se aos estudos econômicos. Em 1976, foi eleito deputado e, em 1983, senador. Napoleoni, junto com Franco Rodano ${ }^{10}$, foi editor da Revista trimestrall ${ }^{11}$, uma renomada revista de difusão das ideias de economia política desse autor. Diante de todo

10 Franco Rodano foi um político, cientista político e filósofo italiano de fé católica e idealista marxista, comumente considerado como o fundador do cattocomunismo. Ele estava entre os fundadores do Movimento Católico Comunista (1943) e, depois, da esquerda cristã (1944-1945).

11 Revista sobre história, política, economia, literatura (aquilo que, segundo Gomes [1996], hoje se consideraria como "estudos políticos"). Teve suas publicações encerradas em junho de 1970. 
esse repertório biográfico institucional e intelectual, sua obra prima, Elementi di Economia Politica, chegou ao Brasil e foi usada como forma de compreensão de uma bagagem teórico-política social-democrata da economia e como referência em diversos setores, inclusive na saúde. Por isso, o texto "A intervenção anticíclica" desse livro serviu de insumo teórico para refletir sobre as análises que Hésio Cordeiro realiza para pensar o SUS no Brasil no decurso da virada neoliberal dos anos de 1980-1990.

\section{CORDEIRO INSPIRADO POR NAPOLEONI: SOLUÇÕES ANTICÍCLICAS PARA PENSAR A SAÚDE PÚBLICA NOS ANOS DE 1980}

O texto de Hésio Cordeiro se refere a uma crítica ao financiamento do setor saúde da época. São relatados os objetivos permanentes das políticas sociais dentro de um Estado democrático - universalização e equidade, ou seja, uma discussão do complexo econômico industrial da saúde, focado no pensamento econômico desenvolvimentista. As discussões voltadas para o financiamento em si tendem a isolar o setor saúde do seu contexto social, discutindo especialmente assistência, e não atenção à saúde.

Quanto ao texto de Claudio Napoleoni (1979), o autor faz algumas definições quanto à economia política, dentro do principal tema: despesa pública. Inicialmente, é contextualizada a situação de recessão e crise econômica, como elas ocorrem, quais são suas causas principais e apresenta duas propostas que ora beneficia o empregado, ora favorece o empregador; no entanto, nesta última situação, é quando discorre sobre a intervenção anticíclica. Neste texto, não há uma discussão específica sobre o setor saúde, mas sim uma avaliação política sobre decisões econômicas dirigidas "para o controle das flutuações cíclicas" advindas do capitalismo. São relatadas as características que originam a despesa pública anticíclica — o modo do seu financiamento, o seu conteúdo e o seu montante.

Para Napoleoni, a despesa seria oriunda de um déficit que confere a ela um caráter efetivamente adicional, e não apenas substitutivo (como no caso do financiamento por meio de impostos). O conteúdo da despesa pública poderia ser direcionado a obras públicas ou subsídios a certas categorias, a fim de gerar demanda e aumento da produção devido à capacidade instalada que estaria ociosa na crise. Por último, são citadas as evoluções econômicas a partir da Segunda Guerra Mundial, quanto a ganhos para a evolução global da atividade econômica a partir do fator de estabilidade e 
do maior consumo determinado pela melhoria salarial conquistada pelas lutas sindicais.

A análise das estratégias de financiamento do setor saúde nos anos de transição democrática foi um importante impulsionador para a reflexão sobre a situação atual da saúde no Brasil, na qual o SUS já está instalado.

Segundo Hésio Cordeiro (1985), o Estado brasileiro de 1985 não era efetivo em suas políticas sociais, pois não eram universais ou promoviam equidade. Em Hésio (1985), as políticas sociais são políticas públicas propostas para garantir o bem-estar geral da população a fim de diminuir a desigualdade social; contudo, naquele período, eram dotadas de um "caráter reconcentrador": "o sentido não redistributivo, ou seja, reconcentrador das políticas sociais do Estado brasileiro é evidenciado nas formas de contribuição ou geração de recursos, no fluxo dos recursos entre os diversos segmentos do complexo médico-industrial e na distribuição dos recursos" (p. 37).

O caráter reconcentrador descrito por Hésio podia ser visto na forma de arrecadação e distribuição dos recursos, uma vez que, em 1984, apenas $5,6 \%$ do produto interno bruto (PIB) foi gasto em saúde, sendo $50 \%$ dos recursos provenientes do setor público. Um número baixo quando comparado ao valor atual de $8 \%$, sendo $45 \%$ correspondentes ao setor público (Organização Pan-Americana da Saúde — Opas Brasil, 2019). Embora tenha ocorrido aumento da parcela do PIB, o valor proveniente do setor público é baixo se comparado a países desenvolvidos com sistemas de saúde semeIhantes, como a Inglaterra que, em 2017, gastou 9,6 \% do PIB, sendo $79 \%$ provenientes do setor público (Cooper, 2019).

Os gastos em serviços públicos de saúde, em 1984, estavam concentrados na esfera federal, $62 \%$, seguido por $27 \%$ na estadual e $11 \%$ na municipal. Atualmente, os percentuais de investimento financeiro são definidos pela Lei Complementar 141, de 13 de janeiro de 2012, na qual os municípios e o Distrito Federal devem aplicar anualmente, no mínimo, 15 \% da arrecadação dos impostos, e os estados, $12 \%$. No caso federal, o montante aplicado corresponde ao valor investido no exercício financeiro anterior e, segundo a Emenda do Teto dos Gastos Públicos (Emenda Constitucional 95/2016), será corrigido apenas pela variação do Índice Nacional de Preços ao Consumidor Amplo pelos próximos 20 anos a partir de 2016.

Já a arrecadação para o financiamento da seguridade social, na qual a saúde se encontra inserida juntamente com a previdência social e a assistência social, em 1982, foi instituído, pelo Decreto-lei 1.940/1982, o Fundo 
de Investimento Social (Finsocial), a primeira tributação incidente sobre as receitas das pessoas jurídicas. Hoje, após quase 40, tem-se o Cofins (Contribuição para o Financiamento da Seguridade Social), que também incide em empresas (Carvalho, 2017). Essa contribuição indireta é transferida ao consumidor final em caráter regressivo, uma vez que é repassado aos preços finais de bens e serviços, incidindo sobre o consumo, e não sobre a renda, o que prejudica famílias de menor renda.

Hésio explicita que havia, em 1985, desequilíbrio entre a necessidade e a oferta de serviço de saúde, uma vez que os serviços especializados ou hospitalares eram privilegiados em detrimento dos serviços básicos, exemplo dado que, em 1981, 85 \% dos recursos foram para o atendimento especializado apenas favorecendo uma pequena parcela da população. Hoje, ainda se encontram dificuldades na distribuição do investimento nos níveis de assistência, por exemplo, com a expansão da atenção básica, muitos municípios encontram gargalos nos serviços de média complexidade, como exames diagnósticos e consultas especializadas (Silva, Carvalho, Cordoni Júnior \& Nunes, 2017).

As dificuldades de arrecadação e distribuição dos recursos do setor saúde acima mencionadas e comparadas entre o cenário de transição democrática de 1985 e o cenário atual sugerem que ainda há grande oportunidade de melhoria no atual financiamento do setor saúde brasileiro. Por isso, detalhamos em quatro seções as preocupações de Cordeiro com a saúde pública à época: 1. o caráter reconcentrador do Brasil no período de transição democrática; 2 a política de recessão econômica e a redução dos gastos públicos em saúde; 3. a garantia dos recursos no orçamento fiscal e 4. a destinação dos recursos para a saúde e as políticas de saúde.

\section{Políticas públicas de saúde e o caráter reconcentrador do Brasil no período de transição democrática}

No artigo "Financiamento do setor de saúde: proposta para a transição democrática", de 1985, o autor Hésio Cordeiro inicia sua análise com uma breve contextualização sobre quais deveriam ser os "objetivos permanentes das políticas sociais" (Cordeiro, 1985, p. 37). Esta seção dá embasamento às suas análises sobre alternativas nas formas de arrecadação, antecipando uma discussão que seria necessária para a viabilização do sistema universal que seria criado em 1988.

Na análise de Hésio, as políticas sociais são medidas tomadas pelo Estado, seja por intervenções como a prestação direta de serviços, de 
subsídios, seja por remuneração de prestadores privados. Essas medidas teriam caráter compensatório (anticíclico), já que sua função é reduzir, a níveis socialmente aceitáveis, as desigualdades sociais ocasionadas por diversos fatores presentes nas sociedades industriais modernas ante a crise. Em resumo, as condições em que se dá o consumo produtivo da força de trabalho e as condições de consumo individual e familiar de bens materiais e não materiais. Os recursos financeiros para a implementação das políticas sociais, de acordo com o autor, devem ser repartidos pela sociedade, de modo a atuar como mecanismo efetivo na redistribuição de renda. Hésio (1985) também destaca que, na transição democrática, as políticas sociais devem convergir para a "universalização ao acesso a serviços que atendam às necessidades sociais básicas [...] e para a equidade quanto à natureza e qualidade destes serviços" (p. 37). A saúde, portanto, é um dos itens cuja universalização requer um financiamento adequado e repartido pela sociedade.

Nesse ponto, o texto de Hésio claramente dialoga com o capítulo "A intervenção anticíclica" do livro Curso de economia política (Napoleoni, 1979). Nesse texto, não há uma discussão específica sobre o setor saúde, mas sim uma avaliação política sobre decisões econômicas dirigidas para o controle das flutuações cíclicas advindas do capitalismo. $O$ autor defende a necessidade de uma despesa pública anticíclica nos momentos de crise do capital para que se possa diminuir o desemprego, um grave aspecto das crises econômicas. A despesa seria oriunda de um déficit, conferindo a ela um caráter efetivamente adicional, e não apenas substitutivo (como no caso do financiamento por meio de impostos). O conteúdo da despesa pública poderia ser direcionado a obras públicas ou subsídios a certas categorias, de modo que gerasse demanda e aumento da produção devido à capacidade instalada que estaria ociosa na crise.

A relação entre a argumentação dos dois autores será melhor detalhada posteriormente, com a descrição das alternativas propostas por Hésio e as decisões políticas de intervenção na economia propostas por Napoleoni. No entanto, é possível antecipar que ambos dialogam na medida em que discutem qual o papel da intervenção do Estado na garantia dos direitos fundamentais - que serão estabelecidos na Constituição brasileira de 1988 - e quais as possibilidades plausíveis para o financiamento destes. Hésio foca sua análise especialmente no direito à saúde, devido à sua atuação como sanitarista e ao contexto histórico na transição democrática da década de 1980 no Brasil. Já Napoleoni discute de que forma um acréscimo à 
despesa pública pode gerar demanda e consequentemente emprego em momentos de crise econômica.

O êxito no cumprimento da constituinte de 1988 requer grandes desafios, principalmente referentes às formas de financiamento em saúde e aos limites de participação de conglomerados empresariais na prestação de serviços em saúde. Ao contrário do planejado para o SUS, os mecanismos de financiamento e prestação de serviços do Inamps eram executados de maneira controversa aos objetivos estipulados pela posterior constituição, estando os princípios da universalização e da equidade do acesso aquém do desejado pela sociedade, agravando a desigualdade social e não distribuição de renda e acesso a serviços.

Segundo Hésio, um dos primeiros obstáculos para se promover o financiamento em saúde de uma forma mais equânime e justa, é especificamente o seu mecanismo de arrecadação. Esses recursos eram provenientes de impostos diretos (60\%) e indiretos (20\%). Os impostos diretos são oriundos do desconto previdenciário diretamente da folha de pagamento dos trabalhadores, enquanto os impostos indiretos estão embutidos nos preços das mercadorias. Esse caráter regressivo de arrecadação consequentemente acaba lesando pequenos comerciantes por possuírem menor produtividade e lucratividade em comparação às grandes empresas, bem como afetando as classes sociais mais vulneráveis, visto que contribuem com a mesma alíquota através dos impostos indiretos do que as classes sociais privilegiadas.

Em diálogo ao texto de Claudio Napoleoni e salientando a importância de se diminuir a desigualdade social e tornar mais justo o pagamento de impostos entre as classes sociais, apresenta o papel fundamental que o Estado tem como financiador em épocas de crise. Uma vez que a situação de pleno emprego não pode ficar à mercê de mecanismos de mercado, o Estado trabalha por meio de políticas econômicas dirigidas para o controle das flutuações da economia, particularmente as atividades econômicas não cíclicas, empregadas para o equilíbrio entre a demanda e a oferta global, resultando na manutenção dos níveis de emprego e preços remunerativos ao mercado. Desse modo, conforme apresentado no parágrafo anterior, seria benéfica a aplicação de métodos de arrecadação equânimes de forma que o nível de consumo adequado se mantivesse para a preservação dos níveis de emprego.

O principal arrecadador desses recursos é o governo federal. Segundo Hésio, ao contrário de outras economias, nas quais os financiamentos são 
distribuídos de maneira mais uniforme entre os governos federal, estadual e municipal, no Brasil, o governo federal, à época, era responsável por $62 \%$ do financiamento em saúde, enquanto os Estados e os Municípios eram respectivamente por $27 \%$ e $11 \%$ desses gastos. Com esse cenário centralizador, ocorre o enfraquecimento dos Estados e dos Municípios em termos político-institucionais, financeiros e administrativos.

Não obstante a isso, com a criação do Finsocial, os Estados e os Municípios se tornaram ainda mais dependentes do governo federal para a captação de recursos em aspectos políticos, bem como "burocráticos", visto que a análise e a negociação de novos projetos feitas individualmente pelo Banco Nacional de Desenvolvimento Econômico e Social atrasavam o investimento em infraestrutura e saúde nos Estados e Municípios.

Além do sistema de contribuição e centralização dos recursos, Hésio também apontou como tendência o crescimento de seguros privados associados a grandes grupos empresariais. Com o crescimento da economia e a ascensão da classe média, o setor privado veio ganhando cada vez mais espaço no setor público mediante o oferecimento de serviços de saúde.

Entretanto, observou-se que a privatização no oferecimento de serviços em saúde não contribuiu com a racionalização dos gastos estatais devido aos seguintes aspectos: duplicidade de gastos; esvaziamento financeiro e técnico-operacional das secretarias estaduais e municipais; elevada ociosidade do setor público, distorções nas formas de compra e venda de serviços entre o Inamps e o setor privado, foco na prestação de serviços especializados, os quais geravam maior excedente em detrimento dos cuidados básicos de saúde.

Em 1984, foram implementadas as ações integradas em saúde e as novas formas de remuneração, cujos objetivos específicos visavam à racionalização do sistema e à melhor articulação entre os governos federal, estadual e municipal. Todavia, a adoção desses mecanismos não foi suficiente para impedir o gasto desnecessário de recursos públicos. Para se obter êxito, segundo Hésio, seriam necessárias negociações com o setor privado a fim de se obter maior controle, avaliação de serviços prestados do setor público e privado, bem como a reavaliação da remuneração de prestadores de serviços.

Outro fator agravante referente à introdução do setor privado na saúde como prestador de serviços foi a própria distribuição de serviços em si. Por apresentar caráter não redistributivo, foi verificado que o gasto per capita 
na região Nordeste do Brasil equivale a menos da metade dos gastos com as regiões Sul e Sudeste. Essa divergência também era observada nos gastos com as populações rural e urbana. Nesse cenário, observava-se explicitamente o interesse do setor privado na prestação de serviços em áreas produtivas e a exclusão do acesso à saúde pelas classes mais vulneráveis, principalmente as localizadas no campo.

Citando Napoleoni (1979), o parágrafo anterior demonstra que cabe ao Estado a responsabilidade de assegurar o acesso à saúde, bem como os recursos necessários para a sociedade de maneira equânime, não devendo essa tarefa ser delegada ao mercado, cujos interesses vão na contramão do bem coletivo.

\section{A política de recessão econômica e a redução dos bbgastos públicos em saúde}

A transferência do capital produtivo para o capital financeiro especulativo, que em nada agrega ao país, pelo contrário, atende apenas aos interesses de parte da elite e dos grupos dominantes, tem sido motivo de amplo debate no Brasil. Para Santos (1990), o governo tinha optado pela priorização da transferência, feita por meio do pagamento da dívida externa (juros, spreads, comissões da dívida), do subfaturamento das exportações, do superfaturamento das importações, da fuga de capitais, da remessa de lucros e dividendos, e do pagamento da dívida interna, atrelada aos bancos privados e às agências financeiras, sob altíssimos juros.

A consequência direta dessa decisão é a redução dos gastos públicos para fazer frente a essas transferências.

Portanto, o cenário brasileiro exibia um quadro de profunda desigualdade social no qual as políticas sociais, em geral, e da saúde, em particular, não tinham sido instrumentos efetivos para o combate e a redução das desigualdades sociais. O grande responsável por essa situação era a constante contração dos gastos públicos.

Naquele contexto, o setor saúde dependia da adoção de medidas inovadoras que lhe garantissem meios mínimos necessários para o seu adequado funcionamento (Cordeiro, 1985). Contudo, a falta de recursos aliada à ausência de vontade política de se priorizar os gastos sociais tinha gerado, ano após ano, a redução, em termos reais, na alocação de recursos para esse setor. 
A reversão dessa tendência passava pela discussão de um conjunto de medidas de curto e longo prazo. Era necessário buscar a otimização da utilização dos recursos, financeiro, físico, material ou humano, aumentando a sua eficiência e resolutividade, diminuindo a ociosidade e melhorando seu gerenciamento. Adicionalmente, a revisão das compras dos serviços privados precisava ser revista. Porém, os limites de eficácia dessas medidas se depararam novamente com a carência de recursos e de vontade política.

A diminuição da atividade econômica tinha provocado a redução da receita fiscal que, por sua vez, levou a uma queda proporcionalmente maior dos gastos públicos, em consequência da priorização da geração do superávit fiscal. Destaca-se o fato de que esse superávit tenha se dado às custas dos cortes dos gastos públicos, incluindo os da área social (Cordeiro, 1985).

Essa situação estava longe de ser solucionada, caso o governo continuasse a priorizar o pagamento dos encargos financeiros das dívidas externas e internas, e não houvesse melhoria na situação econômica do país. As previsões orçamentárias tinham demonstrado que o poder público não tinha a intenção de revê-la a curto prazo, dado que o que se tinha observado era uma contínua redução dos gastos públicos em saúde (Cordeiro, 1985).

Podia-se perceber que, em termos reais, havia uma redução dos gastos do governo no período de 1978-1984 de $13 \%$, uma vez que, em 1984, gastou-se $87 \%$ do orçamento de 1978. Considerando a inflação e o aumento dos custos médico-hospitalares no período, verificava-se a redução efetiva nos gastos do Governo (Cordeiro, 1985). Conforme Daim (1984), entre 1980 e 1984, houve uma redução da receita em 16,7 \% e uma queda da despesa de $21,4 \%$, o que gerou um superávit fiscal, transferido para o orçamento monetário.

A alternativa proposta por Daim (1984), como política emergencial, era a de reverter os procedimentos de geração de superavit fiscal, adotando a opção política por um déficit fiscal temporário que canalizaria a utilização de recursos fiscais para a área social. Ou seja, uma saída anticíclica clássica que tinha nos recursos adicionais a possibilidade de servir para reduzir as desigualdades sociais, e não para acentuá-las como tinha acontecido com a transferência desses recursos para o setor financeiro.

A mudança de proposta fiscal descrita por Hésio se conecta com a ideia de Napoleoni (1979), quando este último autor trata da superação das flutuações cíclicas da economia e sugere a adoção de uma política anticíclica. A intervenção econômica anticíclica, na qual o incremento da despesa pública 
teria um papel relevante, visaria a um aumento maior na renda por meio do reaquecimento da economia.

Para Napoleoni (1979), os três aspectos mais relevantes da despesa pública anticíclica seriam: o seu modo de financiamento, o seu conteúdo e o seu montante.

- O financiamento deve ter um caráter real adicional; dessa forma, a despesa pública deve ser financiada com déficit, não com emissão de títulos públicos, pois isso seriam apenas substituições de poupanças, não teríamos nenhum efeito antidepressivo, portanto deve-se priorizar o financiamento que comporta uma expansão monetária, que não sofreria efeitos inflacionários, pois aumentaria a disponibilidade de trabalho e de outros meios de produção, durante essa fase de recessão (Napoleoni, 1979).

- O conteúdo da despesa pública deve se desenvolver uma demanda adicional, seja por execuções de obras públicas, seja pela política de subsídio a certas categorias da população (Napoleoni, 1979). É importante trazer uma ótica sobre o texto de Cordeiro (1985), no qual ele fala sobre a importância de novas formas de contribuições e benefícios dos previdenciários, podendo utilizar de uma forma mais igualitária o sistema de saúde, trazendo maior benefício à população mais carente.

- O montante da despesa pública no período de recessão, um incremento na renda que permite, assim, um incremento do emprego, gerando assim a possibilidade de efeito cascata, aumentando o número de pessoas empregadas, gerando um efeito positivo na economia como um todo. Esse efeito gera maior lucratividade das empresas, pagamento de trabalhadores e possibilidade de poupanças.

Esse reaquecimento da economia gera fonte de pagamento de impostos, fazendo um paralelo com o texto do Cordeiro (1985). É possível utilizar uma parte desses valores arrecadados para ser mais uma forma de financiamento da previdência social e particularmente do sistema de saúde, podendo direcionar tais valores para programas sociais que impactam diretamente a vida de toda a população.

Para Napoleoni (1979), em termos conceituais, apesar de a despesa pública anticíclica ser aplicada de forma comum como uma intervenção curativa, pode também ser empregada preventivamente. Dessa forma, 
é possível estimular outros setores da economia, mantendo programas de investimentos por meio dessa estabilidade interna. Assim, a despesa pública tem um papel importante na estabilidade da atividade econômica e tem sido motivo fundamental da mitigação da evolução cíclica das crises econômicas na história econômica mundial.

Portanto, considerando-se a precária situação em que se encontrava o sistema de saúde no país, a crise econômica e a alegada falta de recursos, a proposta de Daim (1984) deveria ser ao menos uma alternativa a ser refletida e considerada pelo poder público à época. É por certo que, assim como todas as outras decisões governamentais, deveriam ser tomadas à luz de um forte componente político. No cenário brasileiro de transição democrática de 1985, administrado por um governo ultraliberal, seria quase impossível que fosse adotada. Caberia à população, por meio dos seus representantes, sinalizar, apresentar, reivindicar e lutar por essa alternativa, pois, conforme Napoleoni (1979) sugere, a superação das flutuações cíclicas da economia requer uma ação política diferente da tradicional.

\section{As mudanças necessárias na forma de arrecadação: garantia dos recursos no orçamento fiscal}

Segundo Hésio Cordeiro (1985), à época, os mecanismos de financiamento do setor de saúde deveriam ter como foco a redistribuição espacial e social de renda, o que possibilitaria a expansão do acesso aos serviços de saúde para toda a população.

Além de medidas emergenciais que o autor sugeria, o governo deveria adotar medidas que poderiam gerar resultados sustentáveis no médio prazo na forma de arrecadação, como:

- reforma tributária que fosse realizada para desenvolver uma forma de tributação mais justa, na qual quem tem mais poder aquisitivo pudesse contribuir com uma parcela maior, sendo um imposto progressivo sobre a renda de cada contribuinte, o que permitiria uma taxação mais igualitária, ligada à renda de cada cidadão. Porém, não se poderia permitir um aumento de imposto no âmbito estadual e municipal, que encareceria produtos de consumo, afetando diretamente a classe assalariada, gerando um impacto negativo;

- ampliação de novas fontes de arrecadação e direcionamento de uma parcela maior para os programas sociais; 
- novas ampliações de participações na previdência social, por meio da contribuição das grandes empresas com vistas ao valor agregado da produção;

- melhor distribuição dos valores arrecadados pela união por meio dos impostos para gastos sociais;

- criação de um fundo nacional, estadual e municipal para gerir os recursos orçamentários do Ministério da Saúde, por procedimentos interinstitucionais;

- fixação da parcela de recursos arrecadados pela previdência para a assistência da saúde;

- reestruturação, por meio do Finsocial, da forma de negociação projeto a projeto;

- reestruturação do sistema de saúde pública por meio da revisão das leis do Sistema Nacional de Saúde e da Lei Orgânica da Previdência Social, com a definição de novas formas de contribuição previdenciária e das relações entre os sistemas previdenciário e de prestação de serviço de saúde.

É possível observar que Cordeiro propõe como medidas de melhoria o aumento de arrecadação e a criação de fundos específicos para favorecer a melhor administração dos recursos, por meio de reformulação e reestruturação do sistema de saúde e da previdência.

\section{A destinação dos recursos para a saúde e as políticas de saúde}

O estabelecimento de mecanismos adequados para a obtenção de recursos destinados à saúde deve ser acompanhado de medidas que promovam uma destinação adequada, a fim de garantir a maximização do uso desses recursos e para que se estabeleça uma efetiva melhoria nos padrões e nos indicadores de saúde da população como um todo.

Portanto, é necessário estruturar a maneira como os recursos são destinados à população, considerando as desigualdades sociais existentes, de forma a se garantir a universalização e a equidade desses recursos para as diferentes camadas sociais, especialmente as menos favorecidas.

Deve-se, dessa maneira, reconhecer a importância do contexto econômico-social local para se definir melhor a forma dessa destinação. 
Esse contexto é de grande importância, considerando-se que a redução da renda da população afeta os mais pobres e sua relação com a administração dos riscos e com os cuidados de saúde.

Assim, segundo Cordeiro (1985), esse plano de destinação dos recursos se daria por meio do estabelecimento de medidas com diferentes alcances temporais e com diferentes objetivos, com a inclusão de medidas emergenciais, de curto e de médio prazo.

Nesse sentido, as medidas emergenciais visariam conter o agravamento das condições de saúde das populações de mais baixa renda, com o uso da discriminação positiva como forma de se atingir mais efetivamente essa população, em especial a com renda até dois salários-mínimos ${ }^{12}$ (Cordeiro, 1985).

As medidas de curto e médio prazo seriam voltadas para o desenvolvimento da capacidade gerencial e operativa do sistema público, mediante ações integradas e de forma coordenada entre os diferentes níveis, além de um estabelecimento de novas formas de relação entre o setor público e o privado, elevação de investimento público nos serviços básicos e hospitalares.

A recomendação de medidas que se preocupavam com a utilização da capacidade e da operacionalização do sistema estavam, em certa medida, ainda alinhadas com o pensamento desenvolvimentista, embora já contendo uma crítica às tentativas anteriores de implementação de políticas de saúde tal qual implementadas em países com história e nível de desenvolvimento econômico muito diverso do brasileiro e descoladas de um contexto mais amplo. Nesse sentido, a crítica de Hésio Cordeiro pode ser radicada à análise de Claudio Napoleoni quando este último julga o reformismo e o período histórico porvir da agudização da crise do capitalismo (a qual Cordeiro vivenciava).

Naquele momento, Cordeiro aponta que também já estão presentes recomendações de medidas que viriam a ser orientadoras do SUS, como a de gestão descentralizada, com a delegação de autonomia em nível regional e estadual, elaboração de um orçamento que refletisse uma programação integrada e descentralizada, que viabilizasse uma cobertura assistencial planejada de acordo com as condições de saúde da população,

12 O salário-mínimo, à época, era de Cr\$600.000,00 (Decreto 91.861, de 1985), equivalente a R\$ 670,11 (USD\$124,69), em janeiro de 2020, conforme correção monetária pelo Índice Nacional de Preços ao Consumidor Amplo (Fundação de Economia e Estatística — FEE, 2020). 
a recuperação dos serviços públicos e a participação de provedores de serviços privados.

O caráter de essencialidade da saúde e suas muitas particularidades, incluindo a complexidade das relações entre políticas econômicas e sociais sugeriam a necessidade da construção de outros enfoques que não o meramente estanque e setorizado. Políticas econômicas de austeridade, como a vivenciada naquele período, provocavam impactos diretos e indiretos na saúde, uma vez que, com a diminuição de investimento em ações de prevenção, atenção e cuidados de saúde da população, bem como a redução de investimento em políticas sociais, há impactos na emergência de doenças ligadas diretamente às condições socioeconômicas.

Muito se tinha utilizado o crescimento do PIB como o mais importante indicador de prosperidade econômica, no entanto esse importante indicador isoladamente não é (e nunca foi) capaz de medir de fato a prosperidade econômica de uma nação, salvo seja complementado por outros indicadores de distribuição de renda. Vejamos o exemplo do chamado "milagre econômico", ocorrido durante o regime militar, em que, entre 1968 e 1973, o PIB cresceu em média $10 \%$ ao ano com políticas que favoreceram determinados setores em específico como indústria e habitação (criação do Fundo de Garantia do Tempo de Serviço) (Rovaroto, 2019).

A desigualdade econômica e social afeta a saúde de diferentes formas. Parcelas menos favorecidas da sociedade não possuem recursos materiais (ou dinheiro) para adquirir bens e serviços de saúde, tais como: consultas médicas, medicamentos, planos de saúde etc. ou ainda adquirir uma alimentação correta, o que implica uma dieta fraca e uma situação de imunodeficiência, o que causa maior propensão às doenças.

Geralmente, essas parcelas da população vivem em áreas de alta concentração urbana sem acesso a saneamento básico, o que gera uma grande propensão a problemas infecciosos como diarreia, cólera ou febre tifoide. Outros fatores incluem o acesso ao sistema de saúde, às vezes presentes em áreas distantes, e o menor nível de escolaridade, o que por si só já diminui a predisposição por hábitos saudáveis e preocupações com higiene (Tejada, Jacinto \& Santos, 2014).

Desde o pós-guerra, a aplicação de políticas anticíclicas tem sido amplamente utilizada em diversas economias desenvolvidas. Considera-se que a principal causa para o surgimento de uma crise econômica e da depressão se dá por um desequilíbrio entre a demanda e a oferta global, precisamente 
no sentido de que o mercado não absorve mais a preços remunerativos toda a produção que nele é colocada (Napoleoni, 1979), e como decorrência gera níveis altos de desemprego, o que acentua a crise.

Uma alternativa possível para combater esse fenômeno seria o incremento da despesa pública por meio da emissão de notas em favor do tesouro, que, em um cenário de estagnação econômica, não teria necessariamente efeito inflacionário, porque, diante dele, haveria incremento de produção permitido pela disponibilidade de trabalho e de outros meios de produção. Em relação ao conteúdo do gasto, pode-se pensar em obras públicas e/ou subsídios a certas categorias sempre com o objetivo de geração adicional de demanda e consequentemente aumento dos postos de trabalho, medidas sugeridas por Cordeiro em sua análise.

Não há dúvida que essa despesa pode também ser concebida com caráter preventivo. Para ver como isso pode acontecer, pensa-se num país no qual a despesa nacional global contenha uma quota muito forte de despesa pública: por exemplo, um-quarto da despesa nacional. Ora, isso significa que uma parte bastante considerável da despesa nacional fica fora das flutuações que são características da despesa privada, particularmente, como sabemos, da despesa de investimentos (Napoleoni, 1979).

Isso nos leva a entender que de forma corretiva (durante a crise de oferta $\mathrm{x}$ demanda) ou de forma preventiva uma política de déficit fiscal é uma alternativa para equilibrar a relação oferta e demanda, e consequentemente emprego e renda.

Esse mesmo mecanismo poderia (ou deveria) ser utilizado para o financiamento de políticas sociais, inclusive no desenvolvimento políticas de saúde. Conforme descrito por Hésio Cordeiro (1985), essas políticas sociais, por exemplo, deveriam promover serviços de saneamento básico, alimentação e abastecimento de alimentos, políticas de empregos e de salários, política habitacional e política de benefícios previdenciários, que, no limite, afetam a saúde pública. No entanto, deve ser observado que o setor saúde é um setor intensivo em tecnologias, muitas das quais não bem desenvolvidas dentro do setor produtivo brasileiro, o que gera transferência de recursos a outros países detentores de tais tecnologias. Por exemplo, a construção de um hospital ou outro recurso para atendimento, muitas das tecnologias necessárias para tal política seria obrigatoriamente importada, eliminando o efeito multiplicador de renda local (multiplica- 
dor keynesiano). Nesse sentido, o desenvolvimento da indústria nacional deve ser uma prioridade para o fortalecimento de políticas anticíclicas ou preventivas de aporte de investimento público no desenvolvimento do setor saúde.

\section{CONSIDERAÇÕES FINAIS}

O presente artigo traz as aproximações do pensamento econômico de Hésio Cordeiro às medidas econômicas de caráter anticíclico conforme descrito por Claudio Napoleoni. Hésio, sobre o financiamento do setor saúde situado no período de transição democrática antecedente à Constituição de 1988, foca sua análise especialmente no direito à saúde, devido à sua atuação como sanitarista e ao contexto histórico na transição da década de 1980 no Brasil. Já Napoleoni discute de que forma um acréscimo à despesa pública pode gerar demanda e, por consequência, emprego em momentos de crise econômica tal qual se vivia no Brasil à época.

O texto de Hésio está situado no ano de 1985, quando o Estado brasileiro ainda apresentava um caráter reconcentrador, cuja arrecadação também era um desafio do setor saúde dentro de um cenário de crise política e econômica que não favorecia a redistribuição de renda e a igualdade social. Napoleoni cita um Estado em recessão econômica, no qual cabia intervenção direta para combater a desigualdade e o desemprego, devido aos ciclos econômicos inerentes do capitalismo. Dessa forma, os autores se aproximavam quando ambos sugeriam uma ação emergencial do Estado para reverter tal quadro de crise econômica: uma política anticíclica.

Nessa política anticíclica, é necessária uma medida inovadora, na qual o Estado adota uma política de déficit fiscal temporário ao incrementar o gasto público em ações de política pública, ou seja, que visem reduzir as desigualdades sociais. Tal incremento deve gerar demanda, que leva a um aumento da produção devido à capacidade instalada ociosa e à consequente baixa do desemprego, ponto crítico da crise econômica. Inspirado por esse pensar "o econômico", Hésio propõe mudanças na forma de arrecadação que incentivem positivamente o orçamento fiscal, como reforma tributária com impostos progressivos, novos recursos tributários, reestruturação do Finsocial, entre outras. 
Pode-se concluir que as ações resultantes do investimento público na política anticíclica ${ }^{13}$ poderiam (e deveriam) ser utilizadas para o financiamento das políticas de saúde naquele momento a fim de encontrar uma saída keynesiana potencializadora do financiamento do SUS, o que, de fato não ocorreu. Para isso, também era imprescindível estabelecer adequada destinação dos recursos, conhecendo-se bem o contexto socioeconômico dos locais de investimento, além de ser necessário planejar medidas emergenciais, de curto e de médio prazo. Tais políticas de saúde poderiam incluir a promoção de serviços de saneamento básico, alimentação e abastecimento de alimentos, políticas de empregos e salários, política habitacional, benefícios previdenciários, novas formas de relação entre o setor público e o privado, ou ainda investimento em serviços básicos e hospitalares.

Entretanto, o que se sucedeu foi a criação de um SUS fragilizado financeiramente já em seu nascedouro em 1988. Contudo, o pensamento econômico em saúde pujante de um grande sanitarista como Hésio Cordeiro cumpriu o seu papel naquele momento e serviu para o enfrentamento real de tal conjuntura na tentativa de garantir a sustentabilidade financeira do que hoje, com todas as dificuldades de financiamento, é o maior sistema público de saúde da América Latina.

\section{REFERÊNCIAS}

Adorno, T. W. (2003). Notas de literatura I. Editora 34.

Bauer, M. W. (2000). Análise de conteúdo clássica: uma revisão. Em M. W. Bauer \& G. Gaskell. (orgs.), Pesquisa qualitativa com texto, imagem e som - um manual prático (8. ed., pp. 189-217). Vozes.

Bellofiore, R. (1991). La passione della ragione: scienza economica e teoria critica in Claudio Napoleoni. Edizioni Unicopli.

Boschetti, I. (2016). Assistência social e trabalho no capitalismo. Cortez.

13 A política anticíclica, sugerida por ambos os autores e que não aconteceu naquele momento, foi realizada no Brasil em 2009, devido à crise econômica mundial iniciada em 2008. O aumento de investimento público foi concretizado por meio dos projetos de infraestrutura chamados de "Plano de aceleração do crescimento", como no investimento em obras de saneamento básico, habitação (Programa Minha Casa, Minha Vida), estrutura de Unidades de Atenção Especializada em Saúde e infraestrutura logística em rodovias (Brasil, 2016). Tal iniciativa pode ser encarada como uma estratégia de articulação política e social de caráter redistributivo, pois estimulou a geração de empregos, aumentos reais do salário-mínimo e a formalização do emprego (Machado, Lima \& Baptista, 2017). Isso teve um impacto importante na economia brasileira (de modo "curativo"), pelo menos até 2013. Contudo, devido a outros processos sociopolíticos, a medida foi perdendo sua eficácia. 
Bravo, M. I. S. (2015). Serviço Social e reforma sanitária: lutas sociais e práticas profissionais. Cortez.

Buss, P. M. (1988). Medicina social no Brasil: esboço do perfil de um pioneiro. Cadernos de Saúde Pública, 4(3), 342-348. http://dx.doi.org/10.1590/ S0102-311X1988000300010

Carvalho, D. G. (2017). Contribuição social para financiamento da seguridade social (Cofins): principais entraves (jurídicos e econômicos) e proposta de mudança da Lei no 10.833/2003. Em A. Sachsida (ed.), Tributação no Brasil: estudos, ideias e propostas: ICMS, seguridade social, carga tributária, impactos econômicos (pp. 65-122). Ipea.

Centro Brasileiro de Estudos de Saúde [CEBES]. (2014). Medicina Social e Saúde Coletiva: Nelson Ibañez entrevista Hésio Cordeiro. http://cebes. org.br/2014/03/medicina-social-e-saude-coletiva-entrevista-com-hesio-cordeiro/

Codato, A. N. (2005). Uma história política da transição brasileira: da ditadura militar à democracia. Revista de Sociologia e Política, 25, 83-106. https://doi.org/10.1590/S0104-44782005000200008

Collona, M. (2000). Claudio Napoleoni. Em P. Arestis \& M. Sawyer (orgs.), A biographical dictionary of dissenting economists (pp. 433-441). Edward Elgar Publishing.

Cooper, J. (2019). Healthcare expenditure, UK health accounts: Office for national statistics. https://www.ons.gov.uk/peoplepopulationandcommunity/healthandsocialcare/healthcaresystem/bulletins/ukhealthaccounts/2017

Cordeiro, H. (1985). Financiamento do setor de saúde: proposta para a transição democrática. Saúde em debate, 17, 37-40. http:// docvirt.com/asp/acervo_cebes.asp?Bib=SAUDEDEBATE\&PAS$\mathrm{TA}=\mathrm{N} .17+-+\mathrm{ju} \& \mathrm{pesq}=\& \mathrm{x}=57 \& \mathrm{y}=11$

Daim, S. (1984). Só déficit fiscal financia Programa de Emergência. Economia em Perspectiva, p. 4.

Dantas, A.V. (2017). Do socialismo à democracia: tática e estratégia na Reforma Sanitária brasileira. Editora Fiocruz.

Escorel, S. (1999). Reviravolta na saúde: origem e articulação do movimento sanitário. Editora Fiocruz. 
Fiocruz. (2014). Memorial: conheça um pouco da trajetória e as principais contribuições de Hésio Cordeiro. https://portal.fiocruz.br/sites/portal.fiocruz.br/files/memorial_-hesio_de_albuquerque_cordeiro.pdf

Fundação de Economia e Estatística [FEE]. (2020). Atualização de valores. https://arquivofee.rs.gov.br/servicos/atualizacao-valores/

Fundação Nacional de Saúde/Ministério da Saúde [Funasa]. (2017). Cronologia Histórica da Saúde Pública. http://www.funasa.gov.br/cronologia-historica-da-saude-publica

Gadelha, C. A. G. (2012). Dinâmica dos investimentos no subsistema de base química e biotecnológica. Em C. A. G. Gadelha (ed.), A dinâmica do sistema produtivo da saúde: inovação e complexo econômico-industrial (pp. 47-104). Editora Fiocruz. https://doi. org/10.7476/9788575415931.0004

Gomes, Â. C. (1996). Política: história, ciência, cultura etc. Estudos Históricos —Historiografia, 9(17), 59-84. https://cpdoc.fgv.br/producao_intelectual/arq/542.pdf

Longhi, C. R., \& Gentile, F. (eds.). (2019). Ditadura e violência institucional. EDUC.

Machado, C. V., Lima, L. D., \& Baptista, T. W. F. (2017). Políticas de saúde no Brasil em tempos contraditórios: caminhos e tropeços na construção de um sistema universal. Cadernos de Saúde Pública, 33(2), e00129616. https://doi.org/10.1590/0102-311x00129616.

Mathias, T. S. (2020). Sistema da dívida pública e política de saúde: tratamento incorporado ao debate da saúde coletiva brasileira (tese de doutorado em Serviço Social, Universidade Federal do Rio Grande do Norte). Repositório Universidade Federal do Rio Grande do Norte

Marxists Internet Archive [MIA]. (2020). Seção em português. Claudio Napoleoni. https://marxists.architexturez.net/portugues/napoleoni/index. htm

Ministério da Saúde do Brasil (2019). $8^{a}$ Conferência Nacional de Saúde: quando o SUS ganhou forma. http://conselho.saude.gov.br/ultimas-noticias-cns/592-8-conferencia-nacional-de-saude-quando-o-sus-ganhou-forma

Ministério do Planejamento do Brasil. (2016). Programa de Aceleração do Crescimento (PAC). http://pac.gov.br/ 
Miranda, A. S. (2017). Institucionalidades jurídicas e administrativas de estabelecimentos de saúde nas regiões do Brasil. Novos Caminhos, 16. Pesquisa política, planejamento e gestão das regiões e redes de atenção à saúde no Brasil. https://www.resbr.net.br/wp-content/ uploads/2017/04/Novos_Caminhos_16.pdf

Mondaini, M. (2006). Há trinta anos, o eurocomunismo. https://www.acessa. com/gramsci/?id=535\&page=visualizar

Napoleoni, C. (1979). A intervenção anticíclica. Em C. Napoleoni (org.), Curso de economia política (pp. 357-364). Edições Graal.

Organização Pan-Americana da Saúde [OPAS]. (2019). Países estão gastando mais em saúde, mas pessoas ainda pagam muitos serviços com dinheiro do próprio bolso. https://www.paho.org/bra/index.php?option=com_content\&view=article\&id=5874:paises-estao-gastando-mais-em-saude-mas-pessoas-ainda-pagam-muitos-servicos-com-dinheiro-do-proprio-bolso\&ltemid=843

Paim, J. S. (2007). Planejamento em saúde para não-especialistas. Em G. W. S. Campos et al. (eds.), Tratado de Saúde Coletiva (pp. 767-782). Hucitec-Fiocruz.

Paim, J. S. (2008). Reforma sanitária brasileira:contribuição para a compreensão e crítica. EDUFBA-Fiocruz. https://doi.org/10.7476/9788575413593

Paiva, C. H. A., \& Teixeira, L. A. (2014). Reforma sanitária e a criação do Sistema Único de Saúde: notas sobre contextos e autores. História, Ciência e Saúde-Manguinhos, 21(1), 15-36. http://dx.doi.org/10.1590/S010459702014000100002

Portal Fiocruz. (2020). Galeria de Honra: Hésio Cordeiro. https://portal.fiocruz. $\mathrm{br} /$ personalidade/hesio-cordeiro

Raw, I. (2007). Biotecnologia e Saúde Pública. Revista USP, 75, 6-17. file://C:/Users/Leonardo/Downloads/13616-Texto\%20do\%20artigo-16591-1-10-20120517.pdf https://doi.org/10.11606/issn.23169036.v0i75p6-17

Reichlin, A. (2008). Claudio Napoleoni, 1927-1988. https://www.acessa.com/ gramsci/?page $=$ visualizar\&id $=1003$

Rovaroto, I. (2019). "Milagre econômico" e desigualdade social: o contraste da ditadura. https://exame.com/economia/milagre-economico-e-desigualdade-social-o-contraste-da-ditadura/ 
Santos, N. R. (1990). Como é forjado o espaço das políticas públicas com exemplos da área da saúde. Saúde em debate, 28(5), 5-15. http:// docvirt.com/asp/acervo_cebes.asp?Bib=SAUDEDEBATE\&PAS$\mathrm{TA}=\mathrm{N} .28+-+$ mar. $+1990 \&$ pesq $=\& \mathrm{x}=96 \& \mathrm{y}=9$

Silva, C. R., Carvalho, B. G., Cordoni Júnior, L., \& Nunes, E. F. P. A. (2017). Dificuldade de acesso a serviços de média complexidade em municípios de pequeno porte: um estudo de caso. Ciência \& Saúde Coletiva, 22(4), 1109-1120. https://doi.org/10.1590/1413-81232017224.27002016

Starobinski, J. (2011). É possível definir o ensaio? Remate de males, 31(1-2), 13-24. https://doi.org/10.20396/remate.v31i1-2.8636219

Tejada, C. A. O., Jacinto, P. A., \& Santos, A. M. A. (2014). Pobreza e saúde: evidências de causalidade em um painel de dados para o Brasil. http:// www.economiaetecnologia.ufpr.br/XI_ANPEC-Sul/artigos_pd f/a2/ ANPEC-Sul-A2-17-pobreza_e_saude_evidenci.pdf/ 